\title{
In Beehive Route of Administration
}

National Cancer Institute

\section{Source}

National Cancer Institute. In Beehive Route of Administration. NCI Thesaurus. Code C85517.

Administration of a veterinary medicinal product by placing in or sprinkling over a beehive. 